\title{
EFFECT OF EARTHQUAKE INCIDENCE ANGLE ON SEISMIC PERFORMANCE OF RC BUILDINGS
}

\author{
M. Sri Kanya ${ }^{1}$, B D V Chandra Mohan Rao ${ }^{2}$ \\ ${ }^{I}$ M.Tech. (Structural Engg.) Student, VNR VignanaJyothi Institute of Engg. \& Tech., Bachupally, Hyderabad - 500 090, \\ kanyamullapudi@gmail.com \\ ${ }^{2}$ Professor of Civil Engg., VNR VignanaJyothi Institute of Engg. \& Tech., Bachupally, Hyderabad - 500 090, \\ bdvcmrao@gmail.com
}

\section{SYNOPSIS}

Structural engineer's greatest challenge in today's scenario is constructing seismic resistant structures. In this paper, the influence of the earthquake direction on the seismic response of RC buildings is examined. In this study, three RC buildings, One regular and Two plan irregular buildings (Plus-shape, H-shape) are investigated for critical seismic incidence angle. All the buildings having the same floor plan area are modelled to have a better comparative study. In this paper, all the buildings are subjected to ground accelerations (Northridge earthquake record) in twelve directions whose values ranges between 0 to 180 degrees, with an increment of 15 degrees. The Linear Time History Analysis (LTHA) has been carried out for the above said buildings using ETABS v 15 Software. It is observed from the study that, the structural demand produced varies as the function of incidence angle of the seismic input. The various response parameters studied are axial forces in the columns, maximum storey displacement and storey shear. The results show that angle of seismic input motion considerably influences the response of RC structures.

Keywords : Incidence angle, Plan irregular buildings, Linear Time History Analysis, Column axial forces, Storey displacement, Storey shear

\section{INTRODUCTION}

Linear time history analysis (LTHA) is used now a days to evaluate the seismic performance of tall RC buildings and the effect of incidence angle. The input ground motion is applied to the structures in various angles to principle axes. The critical angle varies for every structure with respect to type of the model, fundamental period etc.

One regular and two plan irregular models are considered for the present study. Three buildings i.e. Regular, Plusshaped and $\mathrm{H}$-shaped buildings are modeled in $\mathrm{E}$ Tabs. These are subjected to seismic forces at a certain incidence angle ranging from 0 - 180 degrees with an increment of 15 degrees. The column forces, maximum storey displacement and storey shears are the various parameters considered for the comparision. Five storeyed building frame is considered for performing Time History Analysis for ground acceleration data Recorded at station Los Angeles-baldwin hills for Northridge Earthquake occurred on January 17, 1994.

\section{LITERATURE REVIEW}

Nonlinear Time History Analysis (NLTHA) of two 5-story steel buildings with square and rectangular plan using the accelerograms of 2 horizontal components of previous earthquakes is carried out by Mahmood Hosseini and Ali Salemi ${ }^{1}$. The data of the earthquakes used has the same PGA level and angle of excitation varies from 0 to 90 degrees with an increment of 10 degrees and it was observed that column axial forces may exceed ordinary cases upto $50 \%$ by varying angle of excitation.

The effect of directionality on the building response has been investigated by means of non-linear dynamic analyses is studied by Paolo Emidio Sebastiani, Laura Liberatore, Andrea Lucchini and Fabrizio Mollaioli ${ }^{2}$. The incidence angles taken from 0 to 180 degrees, with an increment of 22.5 degrees. It has been observed that the equivalent linear and nonlinear 2DOF models may be adequate to predict the most critical angle of incidence.

The influence of angle of incidence of applied bi-directional ground motions on various engineering demand parameters (EDPs) for inelastic structures is studied by Antonio Bruno Rigato $^{3}$. The models considered had various degrees of inelasticity, plan irregularities, 5\% damping ratios, and fundamental periods that ranged from 0.2 seconds to 2.0 seconds. It was observed that the critical angle varied unpredictable with increase in degree of inelasticity.

Evaluation of the seismic directionality effects is performed by C. Cantagallo, G. Camata and E. Spacone ${ }^{4}$ by subjecting 4 different structures to different scaled and un-scaled bidirectional ground motion records oriented along nine incidence angles, whose values are between 0 and 180 degrees, with an increment of 22.5 degrees. 
The influence of the orientation of the ground-motion reference axes, the seismic incident angle and the seismic intensity level on the inelastic response of asymmetric reinforced concrete buildings is studied by I.-K.M. Fontara, K.G. Kostinakis and A.M. Athanatopoulou ${ }^{5}$. It has been observed that inelastic seismic response depends strongly on the above mentioned 3 parameters.

\section{NUMERICAL STUDY}

In the present study, 5 storeyed building frame is considered for performing Time History Analysis for ground acceleration data recorded at station Los Angeles - Baldwin Hills for Northridge earthquake occurred on January 17, 1994. The same analysis is performed for the following models of buildings :

- Regular (R) Building

- Plus (+) shaped Building

- H-shaped Building

3.1 NorthRidge Earthquake Data

- Peak Acceleration $=234.182 \mathrm{~cm} / \mathrm{sec} / \mathrm{sec}$ at $10.40 \mathrm{sec}$

- Peak Velocity $=14.773 \mathrm{~cm} / \mathrm{sec}$ at $15.68 \mathrm{sec}$

- Peak Displacement $=5.791 \mathrm{~cm}$ at $28.14 \mathrm{sec}$

- Hypocenter distance $=18 \mathrm{~km}$

- Magnitude $=6.69$ (Moment Magnitude Scale)

- Time Interval $=0.02 \mathrm{sec}$

- Number of Acceleration Data Points Recorded = 3001

\section{RESULTS \& DISCUSSION}

The results of Time History Analysis in the form of maximum column forces, maximum displacement and storey shear for all the buildings and their percentage variations with respect to regular building were studied.

\subsection{Maximum Column Forces}

The values of maximum column forces and the variation with incidence angle is shown in Figure 5 and Table 1.

For Regular building, the maximum column forces occurred when the peak ground acceleration is applied at 135 degrees, the value increased by $54 \%$ with respect to 0 degrees. For Plus shaped building, the maximum column forces have occurred when the peak ground acceleration is applied at 135 degrees, the value increased by $50 \%$ with respect to 0 degrees. For $\mathrm{H}$ shaped building, the maximum column forces have occurred when the peak ground acceleration is applied at 45 degrees, the value increased by $45 \%$ with respect to 0 degrees.

\subsection{Maximum Story Displacement}

The values of maximum story displacement and the variation with incidence angle is shown in Figure 6 and Table 2.

For Regular shaped building, the maximum story displacement occurred when the peak ground acceleration is applied at 165 degrees, the value increased by $6 \%$ with respect to 0 degrees. For Plus shaped building, the maximum story displacement occurred when the peak ground acceleration is applied at 180 degrees, the value increased by $7 \%$ with respect to 0 degrees. For $\mathrm{H}$ shaped building, the maximum story displacement occurred when the peak ground acceleration is applied at 90 degrees, the value increased by $24 \%$ with respect to 0 degrees.

\subsection{Maximum Story Shear}

The values of maximum story shear and the variation with incidence angle is shown in Figure 7 and Table 3.

For Regular shaped building, the maximum story shear have occurred when the peak ground acceleration is applied along principal axes ( 0 and 90 degrees), the value increased by $6 \%$ with respect to 0 degrees. For Plus shaped building, the maximum story shear have occurred when the peak ground acceleration is applied at 180 degrees, the value increased by $1 \%$ with respect to 0 degrees. For $\mathrm{H}$ shaped building, the maximum story shear have occurred when the peak ground acceleration is applied at 90 degrees, the value increased by $15 \%$ with respect to 0 degrees.

Considering critical incidence angle values of all models, Plus shaped building has shown negligible variation in maximum column force compared to regular building whereas, $\mathrm{H}$ shaped building has shown $13.2 \%$ increase in maximum column force when compared to regular shaped building.

\section{CONCLUSIONS}

$>$ It is concluded that regular and irregular buildings have shown considerable increase in maximum column forces when the peak ground acceleration is subjected at various incidence angles. There has been no considerable changes in maximum story displacement and maximum story shear.

$>$ It is observed that the internal forces of structural elements depend on the angle of incidence of seismic wave with respect to the axes of building plan. Among various internal forces the axial forces of columns are more sensitive to the angle of incidence.

$>$ For both regular and plus shape buildings the maximum column forces occur at an incidence angle 135 degrees whereas for $\mathrm{H}$ shaped building the maximum column forces occur at 45 degrees.

$>$ It can be inferred that $\mathrm{H}$ shaped building is more vulnerable to earthquakes than the plus and regular shaped buildings.

\section{REFERENCES}

[1]. Mahmood Hosseini and Ali Salemi, " Studying the Effect of Earthquake Excitation Angle on the Internal Forces of Steel Buildings Elements by using Non Linear Time History Analyses", The $14^{\text {th }}$ World Conference on Earthquake Engineering, October 1217, 2008, Beijing, China.

[2]. Paolo Emidio Sebastiani, Laura Liberatore, Andrea Lucchini and Fabrizio Mollaioli, "Simple Models to Predict the Most Critical Incidence Angle for Buildings Under Bi-Directional Near-Fault Excitations", Second European Conference on 
Earthquake Engineering and Seismology, Istanbul Aug 25-29, 2014.

[3]. Antonio Bruno Rigato, " Influence of Angle of Incidence on the Seismic Demands for Inelastic Structures Subjected to Bi-Directional Ground Motions", Dissertation submitted to the Faculty of the Graduate School of the University of Maryland, College Park, in partial fulfilment of the requirements for the degree of Doctor of Philosophy, 2007.

[4]. C. Cantagallo, G. Camata and E. Spacone, " The Effect of the Earthquake Incidence Angle on Seismic Demand of Reinforced Concrete Structures", The $15^{\text {th }}$ World Conference on Earthquake Engineering, Lisoba 2012.

[5]. I-K.M. Fontara, K.G. Kostinakis and A.M. Athanatopoulou, "Some Issues Related to the Inelastic Response of Buildings under Bi-Directional Excitation", The $15^{\text {th }}$ World Conference on Earthquake Engineering, Lisoba 2012.

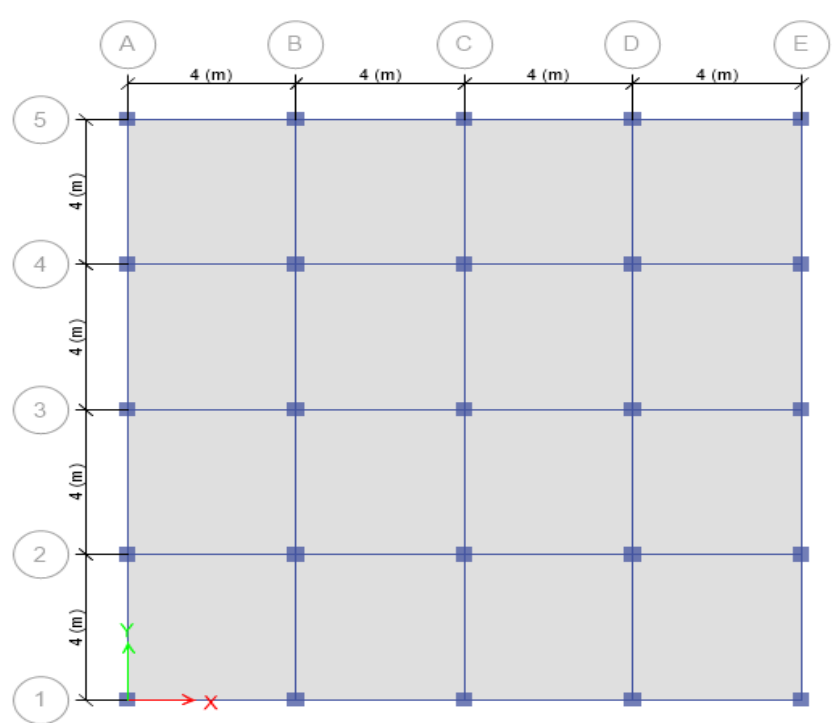

Figure 1: Plan of Regular Building

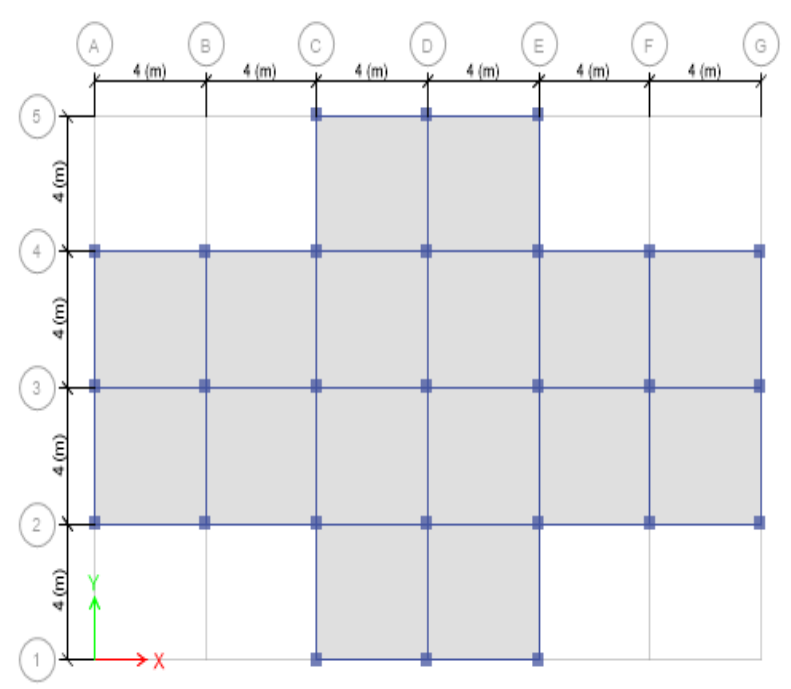

Figure 2: Plan of Plus Shaped Building

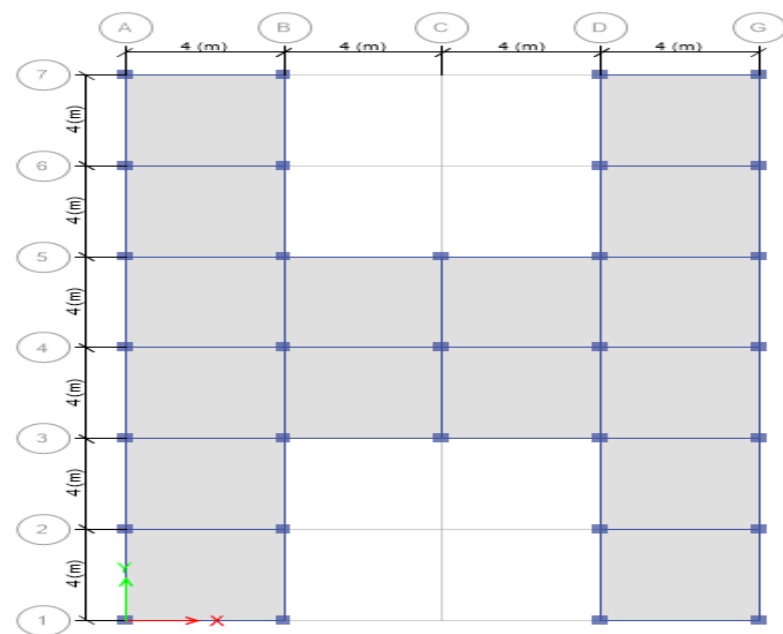

Figure 3: Plan of H Shaped Building

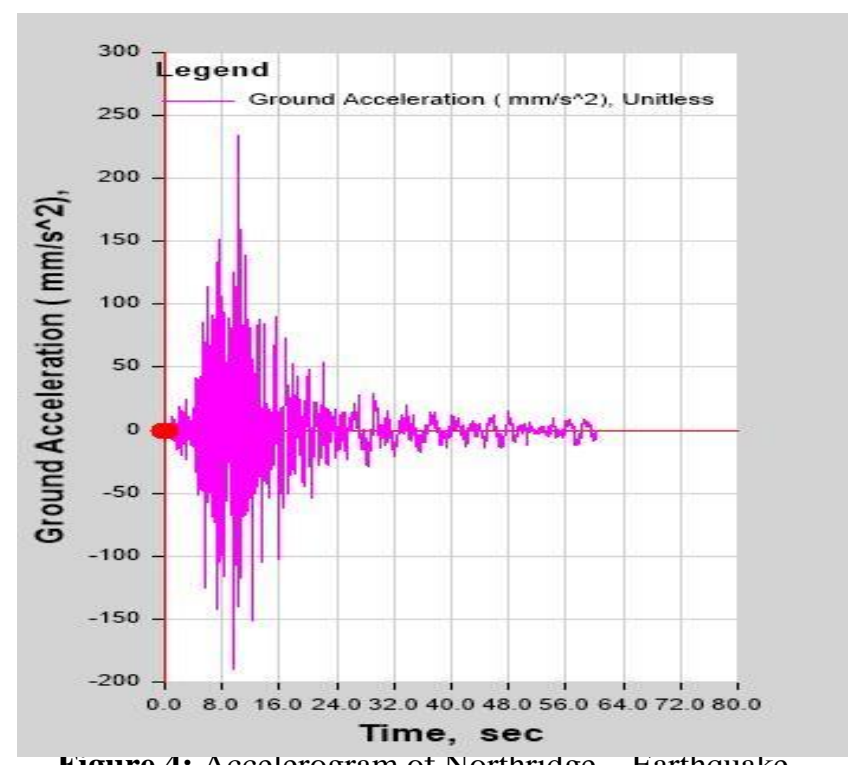

Figure 4: Accelerogram of Northridge Earthquake

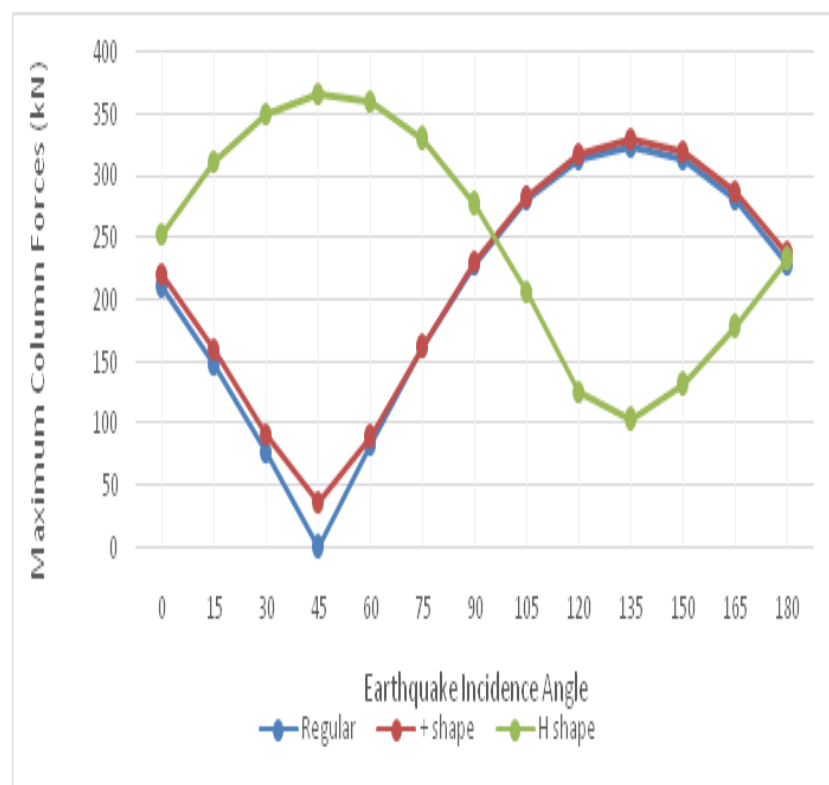

Figure 5: Variation of Maximum Column Forces with Incidence Angle 


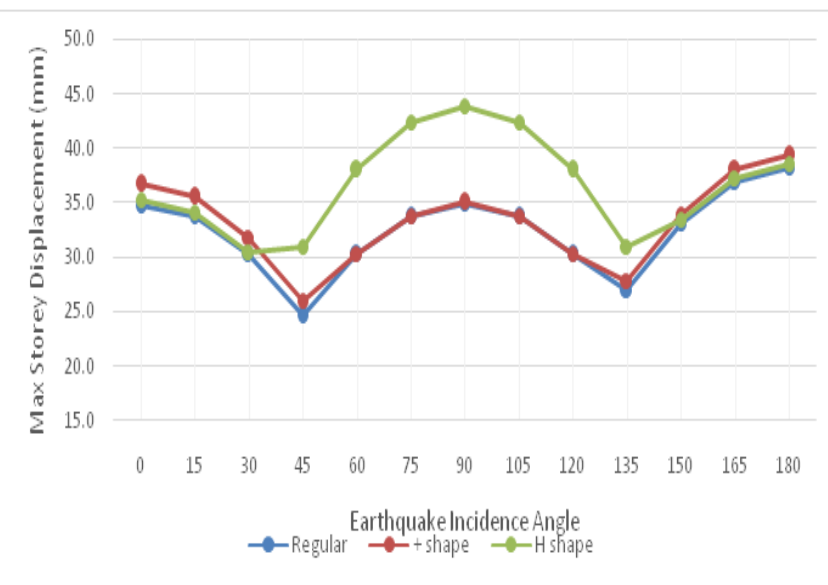

Figure 6: Variation of Maximum Displacement with Incidence Angle

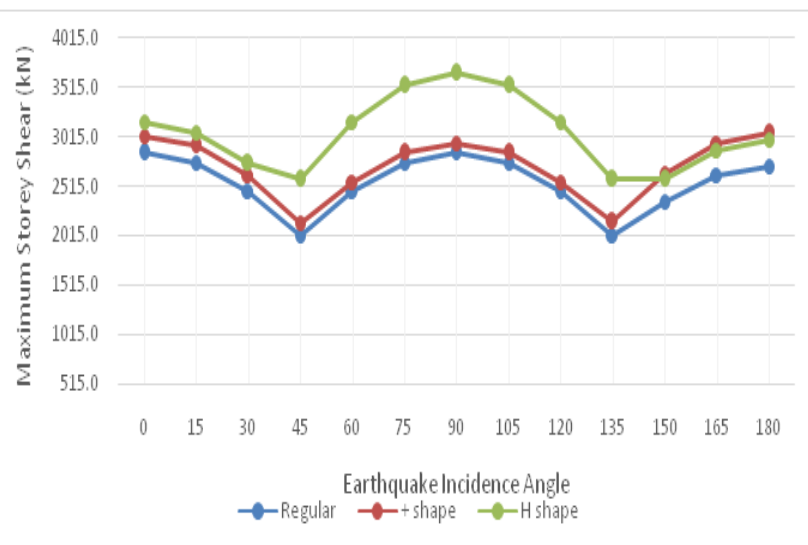

Figure 7: Variation of Maximum Storey shear with Incidence Angle

Table1 - Maximum Column Forces and \% variation

\begin{tabular}{|l|l|l|l|l|l|l|}
\hline \multirow{2}{*}{ Incidence Angle } & \multicolumn{6}{l|}{ Maximum Column Forces $(\mathbf{k N})$} \\
\cline { 2 - 7 } & Regular & \% difference & Plus shape & \% difference & H shape & \% difference \\
\hline 0 & 210.14 & --- & 220.55 & --- & 253.26 & --- \\
\hline 15 & 148.59 & -29 & 160.24 & -27 & 311.36 & 23 \\
\hline 30 & 76.92 & -63 & 92.22 & -58 & 350.99 & 39 \\
\hline 45 & 0.00 & -100 & 37.17 & -83 & 367.09 & 45 \\
\hline 60 & 83.95 & -60 & 88.95 & -60 & 360.27 & 42 \\
\hline 75 & 162.17 & -23 & 161.77 & -27 & 328.91 & 30 \\
\hline 90 & 229.35 & 9 & 230.82 & 5 & 276.69 & 9 \\
\hline 105 & 280.89 & 34 & 284.13 & 29 & 206.80 & -18 \\
\hline 120 & 313.29 & 49 & 318.08 & 44 & 126.53 & -50 \\
\hline 135 & 324.34 & 54 & 330.35 & 50 & 102.90 & -59 \\
\hline 150 & 313.29 & 49 & 320.12 & 45 & 130.85 & -48 \\
\hline 165 & 280.89 & 34 & 288.06 & 31 & 177.67 & -30 \\
\hline 180 & 229.35 & 9 & 236.38 & 7 & 232.11 & -8 \\
\hline
\end{tabular}

Table 2 - Maximum Storey Displacement and \% variation

\begin{tabular}{|l|l|l|l|l|l|l|}
\hline \multirow{2}{*}{ Incidence Angle } & Maximum Storey Displacement $(\mathbf{m m})$ & \multicolumn{4}{l|}{} \\
\cline { 2 - 7 } & Regular & \% difference & Plus shape & \% difference & H shape & \% difference \\
\hline 0 & 34.8 & --- & 36.7 & --- & 35.3 & --- \\
\hline 15 & 33.7 & -3 & 35.5 & -3 & 34.1 & -3 \\
\hline 30 & 30.2 & -13 & 31.8 & -13 & 30.5 & -14 \\
\hline 45 & 24.6 & -29 & 26.0 & -29 & 31.0 & -12 \\
\hline 60 & 30.2 & -13 & 30.3 & -17 & 38.0 & 8 \\
\hline 75 & 33.7 & -3 & 33.8 & -8 & 42.4 & 20 \\
\hline 90 & 34.9 & 0 & 35.0 & -5 & 43.9 & 24 \\
\hline 105 & 33.7 & -3 & 33.8 & -8 & 42.4 & 20 \\
\hline 120 & 30.2 & -13 & 30.3 & -17 & 38.0 & 8 \\
\hline 135 & 27.0 & -22 & 27.8 & -24 & 31.0 & -12 \\
\hline 150 & 33.1 & -5 & 34.0 & -7 & 33.4 & -5 \\
\hline 165 & 36.9 & 6 & 38.0 & 4 & 37.3 & 6 \\
\hline 180 & 38.2 & 10 & 39.3 & 7 & 38.6 & 9 \\
\hline
\end{tabular}


Table 3 - Maximum Storey Shear and \% variation

\begin{tabular}{|c|c|c|c|c|c|c|}
\hline \multirow[t]{2}{*}{ Incidence Angle } & \multicolumn{6}{|c|}{ Maximum Storey Shear $(\mathbf{k N})$} \\
\hline & Regular & $\%$ difference & Plus shape & $\%$ difference & H shape & $\%$ difference \\
\hline 0 & 2849.2 & --- & 3024.6 & --- & 3166.8 & --- \\
\hline 15 & 2752.1 & -3 & 2921.6 & -3 & 3058.9 & -3 \\
\hline 30 & 2467.5 & -13 & 2619.4 & -13 & 2742.2 & -13 \\
\hline 45 & 2014.7 & -29 & 2138.7 & -29 & 2582.2 & -18 \\
\hline 60 & 2467.5 & -13 & 2554.0 & -16 & 3162.6 & 0 \\
\hline 75 & 2752.1 & -3 & 2848.6 & -6 & 3527.4 & 11 \\
\hline 90 & 2849.2 & 0 & 2949.1 & -2 & 3651.8 & 15 \\
\hline 105 & 2752.1 & -3 & 2848.6 & -6 & 3527.4 & 11 \\
\hline 120 & 2467.5 & -13 & 2554.0 & -16 & 3162.6 & 0 \\
\hline 135 & 2014.7 & -29 & 2153.5 & -29 & 2582.2 & -18 \\
\hline 150 & 2352.7 & -17 & 2637.5 & -13 & 2582.8 & -18 \\
\hline 165 & 2624.1 & -8 & 2941.7 & -3 & 2880.7 & -9 \\
\hline 180 & 2716.7 & -5 & 3045.5 & 1 & 2982.4 & -6 \\
\hline
\end{tabular}

